\title{
Correction to: Fungi participate in driving home-field advantage of litter decomposition in a subtropical forest
}

Dunmei Lin • Mei Pang • Nicolas Fanin •

Hongjuan Wang • Shenhua Qian • Liang Zhao •

Yongchuan Yang • Xiangcheng Mi • Keping Ma

Published online: 16 August 2019

(C) Springer Nature Switzerland AG 2019 should presented unitless. Fig 2. has now been corrected.

The original version of this article unfortunately contained a mistake. The labels of y-axes in Fig. 2

The online version of the original article can be found at https://doi.org/10.1007/s11104-018-3865-5

D. Lin $(\varangle) \cdot$ M. Pang $\cdot$ S. Qian $\cdot$ L. Zhao $\cdot$ Y. Yang Key Laboratory of the Three Gorges Reservoir Region's Eco-Environment, Ministry of Education, Chongqing University, 174th, Shapingba Zhengjie Street, Shapingba District, Chongqing 400045, China

e-mail: lindunmei@cqu.edu.cn

\section{N. Fanin}

Interaction Soil Plant Atmosphere (ISPA), UMR 1391, INRA -

Bordeaux Sciences Agro, 71 avenue Edouard Bourlaux,

33882 Villenave-d'Ornon cedex, France

\section{H. Wang}

Biotechnology Research Center, Chongqing Academy of Agricultural Sciences, Chongqing 401329, China

S. Qian · L. Zhao • Y. Yang

National Centre for International Research of Low-carbon and Green Buildings, Ministry of Science \& Technology, Chongqing University, Chongqing 400045, China

X. Mi $\cdot$ K. Ma

State Key Laboratory of Vegetation and Environmental Change, Institute of Botany, The Chinese Academy of Sciences,

Beijing 100093, China 


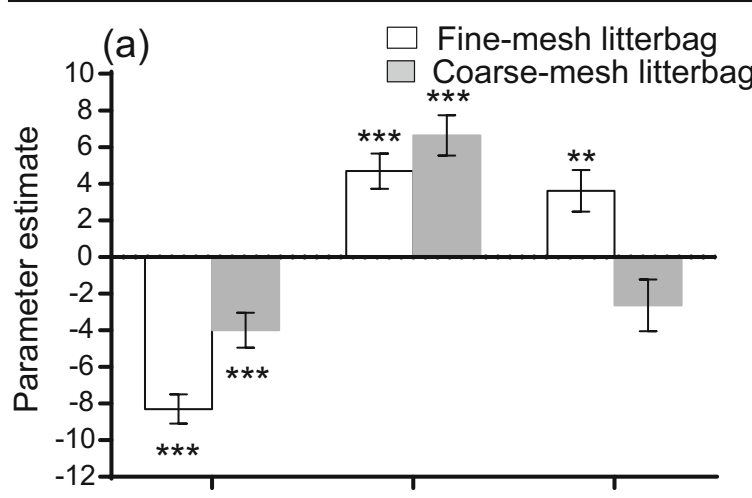

(b)

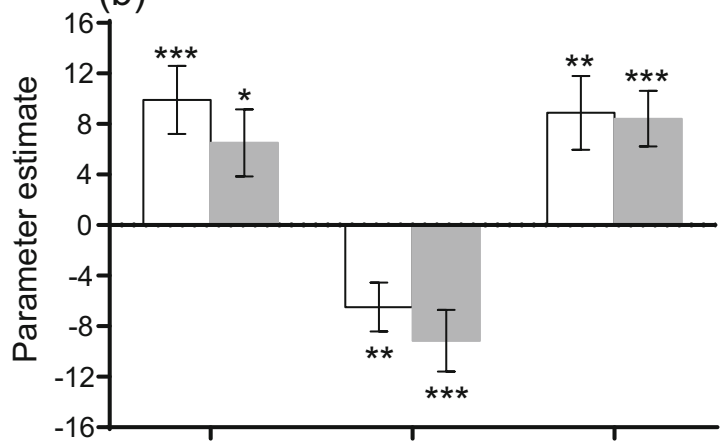

(c)

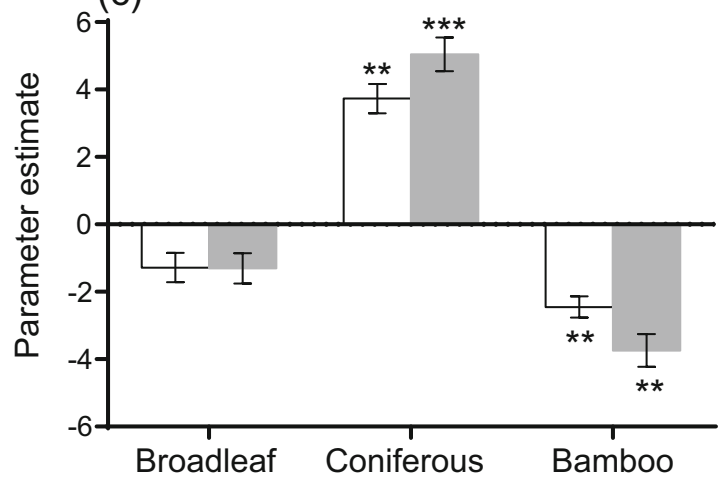

Fig. 2 Parameter estimates (mean $\pm \mathrm{SE}, n=6$ ) of the litter mass loss calculated using the approach developed by Keiser et al. (2014) for (a) litter quality index, (b) home-field advantage (HFA) index and (c) functional ability index. Litter quality index relates to the relative ability of each different litter (broadleaf, coniferous and bamboo) to be decomposed by all the decomposer communities used in our study, HFA estimates the interaction between the litter decomposition and the decomposer communities in each forest (broadleaf, coniferous and bamboo), and functional ability quantifes the overall ability of decomposer community. Data from fine-and coarse-mesh litterbags were analysis separately. Positive values mean positive effect, while negative values means negative effect. Estimates that differ significantly from zero are indicated by asterisk $(* P<0.05$, ** $P<0.01$ and $* * * P<0.001)$

Publisher's note Springer Nature remains neutral with regard to jurisdictional claims in published maps and institutional affiliations. 